WellBeing International

WBI Studies Repository

1992

\title{
The Ethical Judgment of Animal Research
}

Shelley L. Galvin

Western Carolina University

Harold A. Herzog

Western Carolina University

Follow this and additional works at: https://www.wellbeingintlstudiesrepository.org/acwp_arte

Part of the Animal Experimentation and Research Commons, Animal Studies Commons, and the Bioethics and Medical Ethics Commons

\section{Recommended Citation}

Gavin, S. L., \& Herzog, H. A. (1992). The ethical judgment of animal research. Ethics \& Behavior, 2(4), 263-286.

This material is brought to you for free and open access by WellBeing International. It has been accepted for inclusion by an authorized administrator of the WBI Studies Repository. For more information, please contact wbisr-info@wellbeingintl.org.

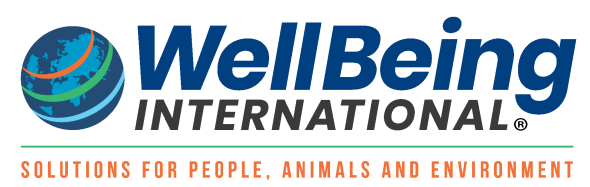




\title{
The Ethical Judgment of Animal Research
}

\author{
Shelley L. Galvin and Harold A. Herzog \\ Western Carolina University
}

\section{KEYWORDS}

animals, ethics, research, moral judgment

\begin{abstract}
One hundred sixty subjects acted as members of a hypothetical Institutional Animal Care and Use Committee and evaluated five proposals in which animals were to be used for research or educational purposes. They were asked to approve or reject the proposals and to indicate what factors were important in reaching their ethical decisions. Gender and differences in personal moral philosophy were related to approval decisions. The reasons given for the decisions fell into three main categories: metacognitive statements, factors related to the animal, and factors related to the design of the experiment.
\end{abstract}

The use of animals as subjects in behavioral and biomedical research has become a major issue with social, political, philosophical, and psychological ramifications (see Baird \& Rosenbaum, 1991, for multiple perspectives on the issue). Largely due to increasing pressure from both animal activists and the public at large, decisions concerning the treatment of experimental animals are no longer routine. Virtually all university-based animal research now comes under the scrutiny of Institutional Animal Care and Use Committees (IACUCs) that must review and approve research projects involving animal subjects. Federal animal welfare regulations mandate that individuals serving on IACUCs represent a variety of perspectives. Hence, individual members of these committees, although being called on to make major decisions about the ethics of research projects, may have little training in moral philosophy, biomedical or behavioral science, or federal animal care statutes.

The decisions that IACUCs make about specific research proposals represent a paradigmatic case of the moral judgment processes as pertaining to the use of animals. Although some investigators have speculated about factors that enter into these decision processes (e.g., Burghardt \& Herzog, 1980), studies directly addressing the psychological processes that influence ethical judgments related to the use of nonhuman species are lacking. Dunlop (1989) used Kolberg's developmental model of moral reasoning to examine boys' stages of moral reasoning about pets. She concluded that lower levels of reasoning were involved in the resolution of ethical dilemmas involving animals than those involving humans. Demographic factors such as gender, ethnic origin, being raised in a rural or urban setting, and individual differences in moral philosophy also influence attitudes toward the use of animals (Gallup \& 
Beckstead, 1988; Galvin \& Herzog, 1992; Herzog, Betchart, \& Pittman, 1991; Kellert, 1988; Pious, 1991; Weunsch, George, Poteat, Castellow, \& Pryor, 1992).

In our study we used qualitative and quantitative methods to investigate the factors that entered into decisions to reject or accept a series of hypothetical proposals in which animal subjects were to be used in research or in educational demonstrations. The study differs from other investigations of attitudes toward the use of animals in research in that the participants were given a detailed description of the proposed research.

\section{METHOD}

Subjects

Participants in the study were 160 undergraduate psychology students (56 men, 104women). They ranged in age from 17 to 42 , with a mean of 19.8 years. The participants were recruited from undergraduate students taking introductory psychology courses at Western Carolina University.

Materials and Procedures

The subjects were asked to assume they had been appointed to serve on a university IACUC. They were given five proposals in which animals were to be used as subjects for research or instructional purposes. The participants were asked to decide whether each experiment should be permitted and to evaluate each proposal on nine dimensions. Finally, following each proposal, the participants were asked to describe in narrative form the factors that they considered in making their decisions.

The proposals were several paragraphs long and were adapted from a classroom exercise (Herzog, 1990). They were based on actual cases and involved various levels of invasiveness, different types of research (e.g., applied vs. pure research, laboratory and field projects), and a range of mammalian species. They included the following:

1. Mice. A neurobiologist proposes to amputate the forelimbs of newborn mice to study the relative influence of heredity and experience on the development of motor patterns (grooming).

2. Rats. A psychologist seeks permission to conduct a classroom learning demonstration. Rats are to be deprived of food for $23 \mathrm{hr}$ and taught to press a lever for food reinforcements.

3. Monkeys. Tissue from monkey fetuses will be implanted into the brains of adult rhesus monkeys to explore the feasibility of neural transplantation as a treatment for Alzheimer's disease.

4. Dogs. Stray dogs awaiting euthanasia in an animal shelter are to be used to teach surgical techniques to veterinary students.

5. Bears. Wild grizzly bears will be anesthetized. Collars containing radiotelemetry devices will be attached to their necks for a study of their social and territorial behavior patterns.

At the end of each proposal was an answer sheet that contained two questions: (a) "Do you think that permission for the research should be granted or denied?" and (b) "On what basis did you make your decision? Discuss the factors or considerations that were important in reaching your decision."

The open-ended question was followed by a questionnaire in which the subjects were asked to evaluate the proposal on nine dimensions using a 9-point rating scale. The questions were partially based on the factors found to be important in ethical judgments of social psychology experiments (Forsyth \& Pope, 1984). The first question, "How ethical do you believe this experiment is?," was rated on a 9-point scale ranging from completely unethical (1) to completely ethical (9). The other eight questions measured were the degree of suffering that would be experienced by the animals in the study, how necessary the 
experiment was to obtain the desired information, the degree of potential benefits of the research, the moral acceptability of the procedures, the likelihood that the experiment would result in important knowledge, whether sufficient precautions would be taken to ensure the well-being of the animals, the applicability of the research to human problems, and how upsetting the participant found the procedures. The participants were also asked to indicate on a 5-point scale, "Do you believe that your moral decisions are based more on your emotions and feelings or more on your thinking and reasoning about right and wrong?"

The subjects completed a series of demographic questions and the Ethics Position Questionnaire (EPQ). The EPQ is a 20-item Likert scale developed by Forsyth (1980) to assess differences in personal moral philosophy. It contains two subscales, one designed to measure idealism and the other designed to assess ethical relativism. Following D. R. Forsyth (personal communication, August 1990), a cutoff value of 6.3 was used to classify participants as high or low in idealism and relativism. This procedure produced a four-cell matrix, with each cell containing individuals holding one of four ethical ideologies: situationist (high idealism and high relativism), subjectivist (low idealism and high relativism), absolutist (high idealism and low relativism), or exceptionist (low idealism and low relativism). The EPQ has been found to be related to attitudes toward animals. Animal-rights activists, for example, typically hold absolutist values, and the EPQ idealism and relativism scales have been found to be correlated with college students' attitudes about the use of animals (Galvin \& Herzog, 1992; Weunsch et al., 1992).

\section{RESULTS}

\section{Approval Decisions}

As shown in Figure 1, the proposals varied considerably on the numbers of subjects who approved them, Cochran's $Q(4, N=160)=152.311, p<.001$. The two proposals involving nonintrusive manipulations were approved most frequently (the bear and rat experiments) followed by the dog, the monkey, and finallY, the mouse studies. It is not surprising that most students rejected some of the proposals; the mouse amputation experiment was rejected by $73 \%$ of the men and $81 \%$ of the women. We were, however, impressed with the number of students who rejected the procedures that might be considered relatively innocuous. For example, $26 \%$ of women and $16 \%$ of men rejected the grizzly bear radio tracking study, and $26 \%$ of women and $19 \%$ of men rejected the study in which rats would be deprived of food for $23 \mathrm{hr}$.

An overall proposal approval score was calculated for each participant by summing the number of proposals that they approved (Figure 2). Men tended to approve more of the proposals $(M=2.98, S D=$ 1.24) than women $(M=2.51, S D=1.12)$, a difference that was statistically significant, $t(158)=2.44, p<$ .05. Ethical orientation was also related to decisions. There was an overall significant effect of ethics position on the number of proposals approved, $F(3,156)=2.75, p<.05$. On average the exceptionists (low idealism, low relativism) approved the greatest number of proposals $(M=3.00, S D=1.24)$ and the absolutists (high idealism, low relativism) approved the fewest proposals $(M=2.39, S D=1.14$ ). Post hoc multiple comparison tests (Tukey HSD) indicated the absolutists and exceptionists were significantly different in the number of proposals approved $(p<.05)$.

The relationships among EPQ rating, gender, and the number of proposals accepted were further analyzed using multiple regression with idealism, relativism, and gender as independent variables and the number of proposals accepted as the dependent variable. There was little relationship between the independent variables; the largest correlation was between gender and idealism $(r=.22)$. Together, the independent variables accounted for only about $5 \%$ of the variance in number of proposals accepted (multiple $r=.27$, adjusted $r^{2}=.054$ ), a finding similar to several other recent studies (Driscoll, 1992; 
Herzog et al., 1991 ). The idealism subscale of the EPQ was the only variable that accounted for a significant portion of the variance $(b=.174, \beta=.192, t=2.433, p=.02)$. However, the amount of variance accounted for by gender was close to being significant $(b=.373, \beta=.151, t=1.895, p=.06)$. The relativism dimension of the EPQ did not account for any of the variance in number of proposals accepted. The predominance of idealism and gender, but not relativism, in explaining the number of proposals accepted closely parallels a prior study in which we found that idealism, but not relativism, was related to attitudes toward animal welfare issues (Galvin \& Herzog, 1992).

FIGURE 1. Percentages of men and women approving each of the research proposals.

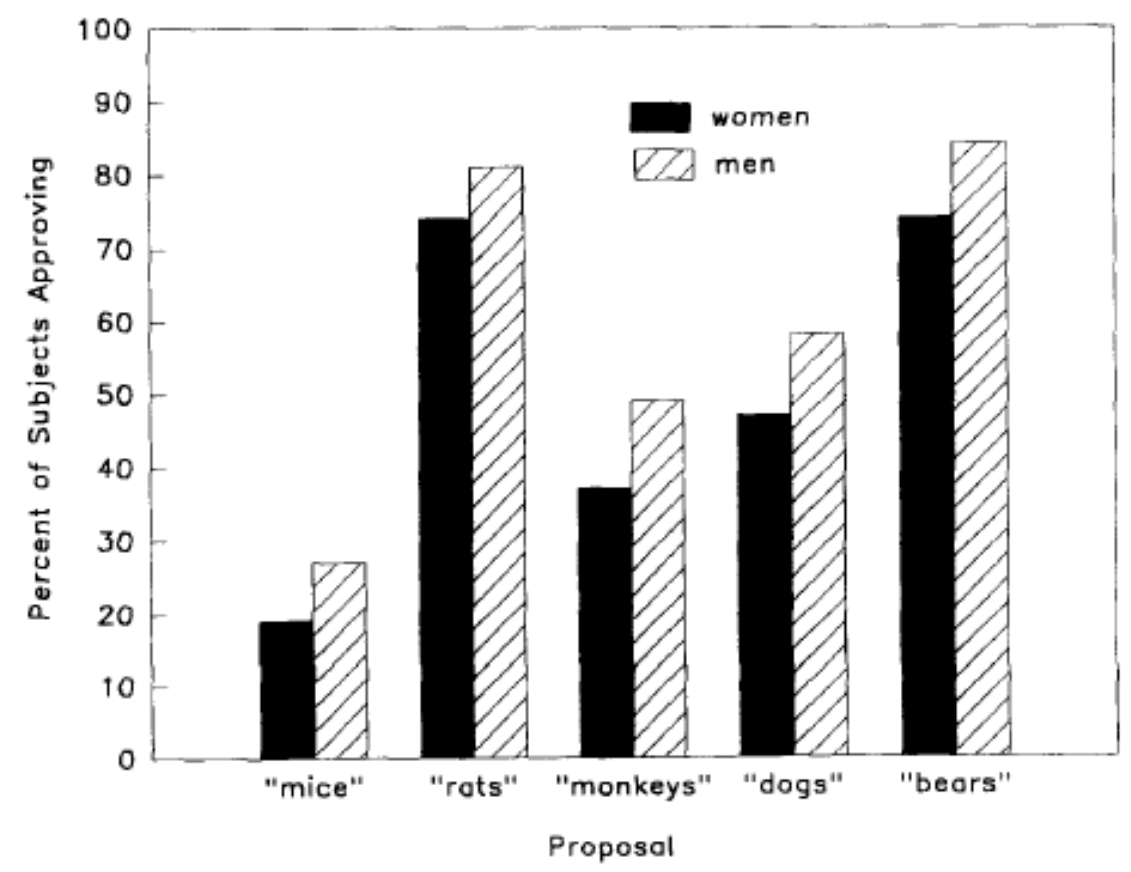

FIGURE 2. Distribution of the number of proposals approved by gender.

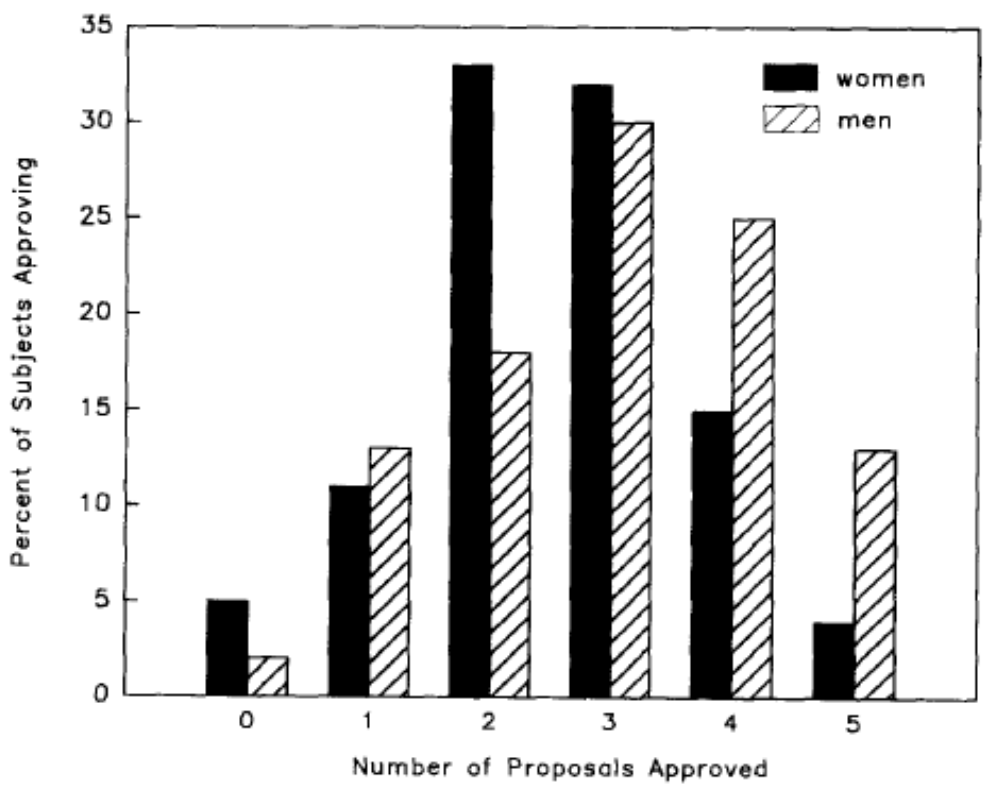




\section{Evaluations of the Proposals}

The proposals varied considerably in how they were evaluated in terms of the nine rating-scale dimensions. The mean ratings given by men and women on each dimension for the five scenarios are summarized in Table 1. Larger means indicate more favorable judgments (i.e., more acceptable) of the proposals on the issues for all questions, except questions on suffering and how upsetting the subject found the proposal.

As expected, Gender X EPQ X Proposal multivariate analyses of variance (MANOV As) showed a significant main effect of proposal, Wilks's lambda $(36,110)=0.89161, p<.01$. A significant main effect of ethics position was also found, Wilks's lambda $(27,400.75)=0.74428, p<.05$. Discriminant analysis (described shortly) was used to follow up the MANOVAs to determine which of the nine dimensions contributed most to the overall difference. The multivariate analysis revealed no overall effect of gender in the rating-scale evaluations of the proposals and no significant interactions. However, an examination of Table 1 shows that women, on average, found all of the proposals more objectionable than men on each of the nine dimensions. The probability of obtaining this pattern by chance on all 45 ratings is low (binomial test, $p<.001$ ).

\section{Predicting Decisions}

We were interested in the degree to which gender, age, EPQ category, the rating-scale evaluations, and the perceived basis for decision making (logic vs. emotion) would predict approval decisions. Discriminant analysis was used to determine which of these variables would predict approval or rejection for each of the five proposals. Table 2 shows the standardized canonical discriminant function coefficients for each prediction variable for each of the proposals. The relative contribution of each of these variables to predicting approval or rejection varied across the five proposals. As Table 2 indicates, perceived benefit of the proposal was the major contributing variable to predicting approval on four of the five experimental procedures. The "ethical" rating and the "moral acceptability of the procedures" rating were significant contributors on four of the five proposals. Other significant variables were specific to the individual proposals. Gender and EPQ category were not significant predictors for any of the proposals. This finding was no doubt due to the fact that there was little variation left to predict after the rating scales were included in prediction equations.

Various combinations of the ratings correctly predicted $95 \%$ of decisions in the case of the mouse proposal, $96 \%$ in the rat proposal, $97 \%$ in both the monkey and dog proposals, and $99 \%$ in the bear proposal. Successful prediction rates in excess of $95 \%$ are extraordinarily high. It is not surprising, however, that decisions to accept or reject the research would be directly related to the evaluations of how moral the experiment was, whether the participant found it upsetting, and so forth.

\section{What Makes an Experiment Ethical?}

We examined the factors that contributed to the judgment of ethicality of the research proposals using regression analysis with the ethical rating as the dependent variable. The independent variables used in the regression were gender, EPQ category, and the rating dimensions shown in Table 3. Standardized regression weights of each variable and the total amount of variance accounted for by the prediction variables (adjusted $r^{2}$ ) are shown in Table 3. As in the case of the discriminant analysis, the proposals differed in how the variables contributed to the regression equations. For example, the major predictor of ethics rating of the mouse proposal was the "upset" rating. In contrast, the major predictor of the ethical acceptability of the monkey experiment was the degree that the experiment was seen as having 
significant benefits. Across most of the proposals, the dimensions of upset and benefits were the major contributing factors.

TABLE 1. Mean Ratings of the Proposals by Gender

\begin{tabular}{|c|c|c|c|c|c|c|}
\hline \multirow[b]{2}{*}{ Gender } & \multirow[b]{2}{*}{$\mathrm{n}$} & \multicolumn{5}{|c|}{ Proposal } \\
\hline & & Mouse & Rat & Monkey & Dog & Bear \\
\hline \multicolumn{7}{|c|}{ How ethical is the experiment? } \\
\hline Women & 100 & & & & & \\
\hline M & & 2.63 & 6.33 & 3.50 & 4.47 & 6.13 \\
\hline SD & & 2.25 & 2.23 & 2.57 & 2.49 & 2.46 \\
\hline Men & 54 & & & & & \\
\hline M & & 3.40 & 6.83 & 4.28 & 5.31 & 7.19 \\
\hline SD & & 2.27 & 2.01 & 2.80 & 2.64 & 1.99 \\
\hline \multicolumn{7}{|c|}{ Do the benefits justify use of the procedures? } \\
\hline Women & 100 & & & & & \\
\hline M & & 2.74 & 5.45 & 4.90 & 5.02 & 5.86 \\
\hline SD & & 2.44 & 2.60 & 2.81 & 2.58 & 2.89 \\
\hline Men & 54 & & & & & \\
\hline M & & 3.28 & 6.02 & 5.67 & 5.72 & 6.93 \\
\hline SD & & 2.37 & 2.30 & 3.05 & 2.59 & 2.25 \\
\hline \multicolumn{7}{|c|}{ Will important scientific knowledge be gained? } \\
\hline Women & 100 & & & & & \\
\hline M & & 3.85 & 3.42 & 6.28 & 5.16 & 5.98 \\
\hline SD & & 2.56 & 2.57 & 2.42 & 2.53 & 2.79 \\
\hline Men & 54 & & & & & \\
\hline$M$ & & 4.13 & 3.54 & 6.39 & 5.91 & 6.80 \\
\hline SD & & 2.65 & 2.46 & 2.54 & 2.29 & 2.21 \\
\hline \multicolumn{7}{|c|}{ How applicable are the results to human problems? } \\
\hline Women & 100 & & & & & \\
\hline$M$ & & 2.43 & 3.34 & 5.94 & 2.98 & 2.71 \\
\hline SD & & 2.03 & 2.47 & 2.52 & 2.24 & 2.16 \\
\hline Men & 54 & & & & & \\
\hline M & & 2.58 & 3.35 & 6.54 & 3.30 & 3.39 \\
\hline SD & & 1.87 & 2.33 & 2.55 & 2.32 & 2.61 \\
\hline \multicolumn{7}{|c|}{ How much suffering will animal subjects experience? } \\
\hline Women & 100 & & & & & \\
\hline M & & 6.87 & 3.77 & 7.71 & 5.84 & 3.29 \\
\hline SD & & 2.10 & 2.08 & 1.80 & 2.57 & 1.60 \\
\hline Men & 54 & & & & & \\
\hline$M$ & & 6.36 & 3.17 & 7.10 & 4.87 & 2.65 \\
\hline SD & & 2.25 & 1.71 & 2.09 & 2.55 & 1.27 \\
\hline \multicolumn{7}{|c|}{ Are precautions sufficient to ensure animals' welfare? } \\
\hline Women & 100 & & & & & \\
\hline M & & 3.47 & 6.84 & 3.46 & 4.31 & 6.45 \\
\hline SD & & 2.45 & 2.13 & 2.42 & 2.65 & 2.27 \\
\hline Men & 54 & & & & & \\
\hline$M$ & & 4.04 & 6.91 & 3.78 & 4.59 & 7.13 \\
\hline SD & & 2.40 & 1.94 & 2.62 & 2.57 & 1.67 \\
\hline \multicolumn{7}{|c|}{ How necessary are these procedures for the desired outcome? } \\
\hline Women & 100 & & & & & \\
\hline M & & 3.20 & 5.21 & 5.60 & 4.89 & 5.99 \\
\hline SD & & 2.55 & 2.61 & 2.64 & 2.52 & 2.56 \\
\hline Men & 54 & & & & & \\
\hline M & & 4.19 & 5.81 & 5.87 & 5.67 & 6.67 \\
\hline SD & & 2.83 & 2.16 & 2.70 & 2.50 & 2.22 \\
\hline \multicolumn{7}{|c|}{ How morally acceptable are the procedures? } \\
\hline Women & 100 & & & & & \\
\hline M & & 2.59 & 6.31 & 3.33 & 4.31 & 6.33 \\
\hline SD & & 2.16 & 2.37 & 2.34 & 2.53 & 2.48 \\
\hline Men & 54 & & & & & \\
\hline M & & 3.38 & 6.56 & 4.09 & 5.17 & 7.35 \\
\hline SD & & 2.15 & 2.13 & 2.76 & 2.61 & 1.81 \\
\hline \multicolumn{7}{|c|}{ How upsetting are the described procedures? } \\
\hline Women & 100 & & & & & \\
\hline M & & 6.89 & 2.90 & 6.74 & 5.59 & 3.10 \\
\hline SD & & 2.53 & 2.41 & 2.50 & 2.62 & 2.40 \\
\hline Men & 54 & & & & & \\
\hline M & & 5.49 & 2.26 & 5.76 & 4.59 & 2.11 \\
\hline SD & & 2.61 & 1.90 & 2.68 & 2.56 & 1.70 \\
\hline
\end{tabular}


TABLE 2. Standardized Canonical Discriminant Function Coefficients of Variables Contributing to the Prediction of Approval

\begin{tabular}{|lccccc|}
\hline & \multicolumn{5}{c|}{ Proposal } \\
\cline { 2 - 6 } Variable & Mouse & Rat & Monkey & Dog & Bear \\
\hline Upset & --- & .557 & --- & --- & --.324 \\
Benefits & .648 & --.577 & .420 & .674 & .662 \\
Precautions & --- & .198 & .150 & .274 & --- \\
Knowledge & --- & --- & --- & .116 & --- \\
Suffering & --- & .277 & --- & --- & --.178 \\
Basis & --- & .218 & .098 & --- & --.197 \\
Ethical & .474 & --.470 & .544 & .380 & --- \\
Applicable & --- & .124 & .238 & .182 & --- \\
Acceptable & .126 & .424 & .170 & --- & .212 \\
Age & --- & --- & .131 & --- & -- \\
\hline
\end{tabular}

TABLE 3. Standardized Beta Weights of Variables Predicting Individual Morality Scores

\begin{tabular}{|lccccc|}
\hline & \multicolumn{5}{c|}{ Proposal } \\
\cline { 2 - 6 } Variable & Mouse & Rat & Monkey & Dog & Bear \\
\hline Upset & --.395 & --.411 & --.201 & --.406 & --.313 \\
Benefits & .306 & --- & .472 & .351 & .455 \\
Precautions & .175 & .160 & --- & .149 & --- \\
Knowledge & .120 & --- & --- & -- & -- \\
Suffering & --- & --.411 & --.145 & --- & --.175 \\
Necessity & --- & --- & .181 & --- & --- \\
Ethics position & --- & --- & .107 & --- & -- \\
Applicability & --- & --- & --- & .107 & - \\
Total variance & .767 & .704 & .703 & .745 & .728 \\
predicted & & &
\end{tabular}

\section{DISCUSSION}

The quantitative portion of this study produced several important findings. Even among a relatively homogeneous group of subjects there were substantial individual differences in the decision to approve or reject scientific uses of animals. There were also large differences in the acceptability of the different proposals. These findings in themselves are not surprising. However, they are important in two respects. First, almost all the participants voted not to approve some research projects; even apparently benign projects were rejected by a substantial minority of a sample of students from a relatively conservative part of the country. The second point is methodological. The details of the procedures were important in the final decision. Many surveys that assess public attitudes toward the treatment of animals lump scientific uses of animals into a single statement (i.e., "Animal research is immoral and should be stopped"). As Driscoll (1992) recently pointed out, this practice inevitably produces a distorted picture of public sentiment toward the use of animals in research.

Although the quantitative approach just described is useful for understanding certain aspects of the psychology of moral judgment, it is an indirect approach to how moral thinking occurs. To capture more 
fully the flavor of the decision-making process, we used qualitative techniques to analyze responses to the open-ended questions.

\section{ANALYSIS OF NARRATIVES}

The aim of the qualitative component of this study was to characterize self-reported internal decisionmaking processes the participants used to resolve the decisions to approve or reject the animal research proposals. The narrative responses of the 154 initial subjects to the question, "On what basis did you make your decision?" were subjected to content analysis (e.g., Patton, 1990). Prior to this analysis, seven of the original subjects and seven additional individuals were interviewed about their responses to the hypothetical proposals. The interviews were used to facilitate the development of a system of categorizing the themes that emerged from the written protocols.

We then conducted a content analysis of the 805 written responses. The statements were read initially to provide an overview of the range of responses. We then developed a category system for use in the subsequent analysis. The protocols were reread and each statement was classified according to the category system. In cases in which more than one theme was present in a single statement, it was included in each category. Finally, every 10th response was independently coded by a trained alternate rater to establish interrater reliability of the system. Interrater reliability was $89 \%$ across the categories.

\section{RESULTS}

The statements describing the decision-making process fell into three broad categories: (a) metacognitive statements in which subjects reflected on their own thought processes, (b) factors related to characteristics of the animal or species, and (c) factors related to aspects of the research such as the experimental design. The three categories together with their subcategories are summarized in Table 4.

\section{Metacognitive Statements}

The participants frequently referred directly to their mental decision-making process. These statements fell into two groups: statements describing how the participant generally approached moral decision making and statements referring to the participant's philosophy of life. The percentage of individuals using each of the categories and their subcategories are shown in Table 5.

\section{Approaches to Moral Decision Making}

Projection. Some participants judged the experiment by imagining themselves or other humans as the research subjects. Projection of the self into the situation was exemplified by a participant who wrote, "How would you enjoy being at home watching your favorite TV show and out of the clear blue sky be shot with a tranquilizer gun?" In justifying his decision to approve the rat experiment a subject said, "Food deprivation for 23 hours is not totally unbearable. I know this from personal experience." Another subject, commenting on the dog experiment, wrote, "We don't tum to orphanages or shelters for the homeless people [to get subjects] for doctors to practice on." In reference to the mouse experiment, a subject made this analogy, "Let's take a newborn human child, cut out its tongue and see if it can learn to spit. That's what the experiment seems like to me." Analogies also were used by those approving research projects. In accepting the use of dogs in veterinary student surgeries, a subject stated, "I think this is basically like humans who donate their organs after their death."

Emotion and logic in moral judgment. The interplay of emotional reactions and reasoned analysis was a theme that emerged from the analysis of the protocols. Some respondents described their emotional reactions to specific proposals. Statements such as "This experiment is horrifying to me" and "It repulses 
me" were common. Procedures were sometimes described in terms such as "gut wrenching," "very scary," and "disgusting." Such affective reactions were sometimes associated with visual images of animal sutfering" Think of the expression on the poor animal's face," and "It's just hard to picture a little mouse without front legs." Not surprisingly these types of responses were typically given by individuals who rejected the proposals. This was also true of individuals who professed love for animals-"First of all, I love dogs" and "Anyway, I like monkeys." In contrast, statements of personal dislike for a species were usually given by those who approved the proposal (e.g., "I hate rats!").

\section{TABLE 4. Themes Discussed in the Decision-Making Process to Approve or Reject Proposals}

I. Metacognitive factors

a. Approches to moral decision making

i. Projection

ii. Emotion and logic in moral judgment

iii. Cost-benefit analysis

b. Philosophical beliefs
i. Rights
ii. Life and death
iii. Nature

II. Factors related to the animal

a. Phylogenetic considerations

b. Labels

c. Capacity to suffer

d. Health

e. Age

f. Relative abundance

g. Attractiveness

III. Factors related to the experiment
a. Cost
b. Benefits
c. Validity
d. Alternatives
e. Likelihood of success
f. Experimenter's motives

A few subjects explicitly discussed the role that logic and emotion played in their evaluations of the proposals. Comments directed toward the logic of arguments were generally made in response to the veterinary school proposal. Arguments for and against the use of dogs in practice surgeries were part of the description of the proposal, and some subjects referred to these arguments in their narratives. For example, one participant wrote: "The arguments of the animal rights groups [given in the proposal] are inconsistent." In contrast, another wrote, "The points that the [animal rights] activists made are good. Their argument seems totally logical."

Some subjects emphasized the role of emotion in their decision. A woman wrote, "The basis of all moral decisions is emotionality. Otherwise, we're not human." Others, however, were not as comfortable with the role of emotion in their decision-making process. Several participants expressed the need to separate emotion from logic in the moral judgment process. This struggle was epitomized by a man who stated, "No matter how logically you look at these cases, your personal feelings will get in the way. My feelings would dictate that all the little animals should live free and happy, and we should never hurt anything. But then, there's no progress, and you've got to go back to being logical." 
TABLE 5. Percentages of Individuals Discussing Metacognitive Variables in Their Approval Decisions

\begin{tabular}{|c|c|c|c|c|c|c|c|c|c|c|}
\hline \multirow[b]{3}{*}{ Theme } & \multicolumn{10}{|c|}{ Proposal } \\
\hline & \multicolumn{2}{|c|}{ Mouse } & \multicolumn{2}{|c|}{ Rat } & \multicolumn{2}{|c|}{ Monkey } & \multicolumn{2}{|c|}{ Dog } & \multicolumn{2}{|c|}{ Bear } \\
\hline & Yes & No & Yes & No & Yes & No & Yes & No & Yes & No \\
\hline \multicolumn{11}{|c|}{ Approaches to Moral Decision Making } \\
\hline Projection & 0 & 13 & 10 & 11 & 2 & 11 & 2 & 5 & 3 & 6 \\
\hline $\begin{array}{l}\text { Emotional } \\
\text { Reaction }\end{array}$ & 22 & 20 & 3 & 14 & 15 & 17 & 9 & 24 & 3 & 0 \\
\hline Logical Analysis & 0 & 0 & 0 & 0 & 9 & 4 & 11 & 15 & 0 & 0 \\
\hline $\begin{array}{l}\text { Cost-Benefit } \\
\text { Analysis }\end{array}$ & 35 & 52 & 73 & 75 & 69 & 38 & 35 & 11 & 80 & 67 \\
\hline \multicolumn{11}{|c|}{ Philosophical Beliefs } \\
\hline Rights & 3 & 9 & 1 & 9 & 0 & 18 & 3 & 13 & 1 & 6 \\
\hline Life and Death & 6 & 2 & 3 & 0 & 8 & 26 & 54 & 21 & 4 & 9 \\
\hline Nature & 3 & 10 & 1 & 5 & 14 & 14 & 4 & 7 & 5 & 13 \\
\hline
\end{tabular}

Cost-benefit analysis. The most common theme in the narratives reflected a process in which the participants weighed the potential benefits of the research with its costs. Usually, these analyses were couched in terms of the suffering of animals pitted against the potential rewards for humans. For example, a woman wrote, "To live in cages, have traumatic surgery and then be killed is not worth saving a bunch of barbaric humans." This type of thinking was summarized succinctly in statements such as, "The learning benefits far outweigh the hardships which the rats will endure" and "What truly far reaching benefits are going to result from mutilating defenseless mice?" Some individuals attended exclusively to the potential benefits, whereas others described only the costs of the research. However, there was considerable diversity as to what subjects judged to be worthwhile versus trivial benefits and minimal versus exorbitant costs. These are discussed later in the context of decision factors associated with the experimental procedures.

\section{Philosophical Beliefs}

As part of their narratives, some subjects described their general ethical philosophy. These included statements about rights and responsibilities, attitudes toward the meaning of life and death, and the participants' assumptions about natural order.

Rights. The concept of rights was central to the thinking of some subjects, particularly in relation to the monkey proposal. Rights were invoked by both those rejecting and those approving proposals. Some participants felt that humans have the right to use animals in the search for treatments of illness. Only a few overtly expressed the common theological view that God gave humans dominion over the Earth's creatures. In contrast, the concept of rights was also used to deny permission to conduct research: "He (the scientist] has no right ... " and "Humans do not have the right .... "

Following the thinking of some animal rights philosophers (e.g., Regan, 1983), some participants argued that animals have fundamental rights that supersede any need we might have to use them in research or education. Statements such as, "Monkeys have as many rights as we do" and "Animals have rights too" were common. A few participants wrote that if animals were given a choice, they would probably not volunteer to be experimental subjects. 
Life and death. In justifying decisions, some respondents alluded to their general views on matters of life and death. Assumptions about life were refleeted in statements such as, "I don't squash bugs. Life is a miracle. It's all precious" and "The animals [dogs] have a greater purpose than to be used as practice for veterinary students." On the other hand, many responses reflected the belief that human life is inherently more valuable than that of animals. This view was exemplified by the participant who wrote, "I believe humans are the supreme beings, and if monkeys can be used to help people live more full and prosperous lives, so be it."

Participants also brought their basic beliefs about death to bear on their decisions. To some, death of animals at the hands of humans is always immoral. This view was articulated by the person who stated, "We should not be allowed in any situation to play God! No moral being has the right to take lives. I believe that we humans take our place in the world too far." On the other hand, some participants felt that the death of animals in the pursuit of higher aims could provide meaning that their "natural" death would otherwise be lacking. This was particularly true in the proposal in which dogs scheduled for euthanasia were to be used for training veterinary students. Subjects wrote that the unwanted dogs should be used for practice surgery to avoid the wasting of life. Others, however, rejected this proposal, insisting that using the animals for practice surgery did not afford them death with dignity.

Natural order. Another category of responses addressed the participants' sense of what might be called "natural order" in the universe. Assumptions regarding the subjects' views of nature were illustrated by statements such as, "Why do we need to know everything about every creature that roams the earth? It's nature." In a rather bizarre twist on the naturalistic fallacy, one subject wrote, "Alzheimer's disease is natural, and if someone gets it, fine." Another stated, "Nature did not intend for animals to suffer for us, for our diseases. They were put here to play."

Factors Related to the Animal

The second major thematic category included statements in which the subjects described characteristics of the animals that influenced their decision. The percentages of subjects identifying these characteristics as important are shown in Table 6.

TABLE 6. Percentages of Individuals Discussing Variables Related to the Animals

\begin{tabular}{|c|c|c|c|c|c|c|c|c|c|c|}
\hline \multirow[b]{3}{*}{ Theme } & \multicolumn{10}{|c|}{ Proposal } \\
\hline & \multicolumn{2}{|c|}{ Mouse } & \multicolumn{2}{|c|}{ Rat } & \multicolumn{2}{|c|}{ Monkey } & \multicolumn{2}{|c|}{ Dog } & \multicolumn{2}{|c|}{ Bear } \\
\hline & Yes & No & Yes & No & Yes & No & Yes & No & Yes & No \\
\hline \multicolumn{11}{|c|}{ Factors related to the animal } \\
\hline $\begin{array}{l}\text { Phylogenetic } \\
\text { considerations }\end{array}$ & 9 & 5 & 2 & 3 & 22 & 24 & 4 & 4 & 0 & 3 \\
\hline Labels & 6 & 0 & 1 & 0 & 0 & 0 & 51 & 55 & 0 & 3 \\
\hline $\begin{array}{l}\text { Capacity to } \\
\text { suffer }\end{array}$ & 6 & 3 & 0 & 3 & 2 & 1 & 1 & 3 & 0 & 0 \\
\hline Health & 3 & 3 & 0 & 0 & 0 & 15 & 2 & 11 & 0 & 0 \\
\hline Age & 16 & 14 & 0 & 0 & 2 & 18 & 0 & 0 & 0 & 0 \\
\hline $\begin{array}{l}\text { Relative } \\
\text { abundance }\end{array}$ & 19 & 0 & 3 & 0 & 3 & 4 & 2 & 1 & 9 & 6 \\
\hline Attractiveness & 0 & 0 & 0 & 0 & 0 & 1 & 0 & 0 & 0 & 0 \\
\hline
\end{tabular}




\section{Phylogenetic Considerations}

The phylogenetic position of the species to be used in the experiment was commonly mentioned by the subjects as a major factor in the decision-making process. For example, a participant justified the use of mice by claiming, "They're just mice. I hardly believe cruelty to animals applies to mice!" Phylogenetic status was invoked by both those who approved and those who rejected the same proposals. For example, the view that "monkeys are the most like humans in the animal kingdom" was expressed by participants who approved the proposed neural transplant study. In this case, the similarity between monkeys and humans justified the research as the results were more likely to be applicable to humans. However, the close relationship between humans and other primates was also cited as a reason to reject the same proposal; monkeys should not be subjected to experimental procedures that would not be approved if conducted on human beings.

\section{Labels}

The labels and roles assigned to a species (e.g., pet, pest, subject, food) affect its moral status (Arluke, 1988; Herzog, 1988). In our study, the moral consequences of labels were most apparent in the case of the dog proposal. Participants who referred to dogs as pets invariably rejected the proposal to use poundseizure animals in practice surgery. One subject wrote that a dog that had been a pet should never be subjected to the "horrors" of practice surgery. Others, however, wrote that the status of pet was transient and did not apply to animals in shelters. Subjects who referred to rats and mice as pests almost always approved their use in the experiments.

\section{Capacity to Suffer}

There are two competing philosophical bases for the animal-protection movement: one based on a utilitarian approach to ethics (e.g., Singer, 1975) and the other based on a deontological view of morality (e.g., Regan, 1983; Rollin, 1981 ). The cornerstone of both of these views, however, is that creatures having sentience (i.e., the capacity to experience pleasure and pain) are entitled to moral consideration. In our study, one of the most frequently mentioned species characteristic that entered into the moral calculus was the degree to which the participants felt that the species could experience pain. Many subjects seemed to assume that animals suffer in ways similar to humans. Other subjects, however, denied that the capacity for these types of mental experiences exists in nonhuman animals. One man wrote, echoing Descartes, "Animals are only made of body, unlike humans who are body, soul and spirit. Despite all that is done to them, they do not suffer."

\section{Health}

The fact that the animals to be used were healthy prior to the proposed research was a consideration in the decision to reject proposals for some participants. For example, some participants denied permission for the use of healthy, unwanted dogs for veterinary student surgeries but said that they had no objections to students practicing on sick or injured animals. Several subjects made the unrealistic suggestion that naturally brain damaged or retarded monkeys be used in the neural transplant study instead of healthy animals.

Age

The age of experimental subjects was a factor in consideration of the mouse amputation and the monkey fetal transplant proposals. As with the phylogenetic theme, age was used both to justify and to reject proposals. For example, in approving the amputation study, a participant wrote, "If the amputation is done when the animal is newborn, it won't know the difference." In contrast, a person who rejected the proposal 
wrote, "I guess the reason that this proposal bothers me is because of the word 'baby.' Baby means innocent."

\section{Relative Abundance}

The conflict between the interests of a species and those of individual animals is the subject of considerable debate within the animals rights and environmental movements (Knox, 1991 ). The relative abundance of the species was an important mitigating factor in two ways. The first pertained to rare species. Some subjects wrote that they rejected the grizzly bear study because it might harm a threatened species. Others, however, pointed out that the bear research might produce information that could contribute to conservation efforts and help increase bear populations. Some responses reflected the belief that it was more important to preserve a species than respect the rights of individual animals.

The second way that abundance entered the decision-making process pertained to abundant species. Many participants referred to the large numbers of mice, rats, and unwanted dogs in approving proposals involving these species. For example, a participant wrote, "Until there is not such an overpopulation of these animals, there is nothing wrong with finding out something positive out of it [the research]." Another said, "There are millions of mice, all of which I hate. I don't think using them for research will endanger the species at all." Another wrote, "There are so many rats around that even if it did involve hurting them, I would grant [approval]. How many rats are killed by poison or in traps for no reason?"

\section{Attractiveness}

Animal advocates are often criticized by their opponents for uncritical anthropomorphism and for being overly concerned with animals that are cute (Jasper \& Nelkin, 1992). We were surprised that only a few subjects mentioned the attractiveness of the animal species as a factor in their decision to approve or reject the research. Subjects who described animals as attractive in their written protocols inevitably rejected the proposal. This occurred in cases of the monkey and dog proposals. In the latter, a participant expressed the incorrect belief that only ugly dogs would not be adopted at animal shelters, so that it would be legitimate to use them in veterinary schools.

TABLE 7. Percentages of Individuals Discussing Variables Related to the Experiment

\begin{tabular}{|c|c|c|c|c|c|c|c|c|c|c|}
\hline \multirow[b]{3}{*}{ Theme } & \multicolumn{10}{|c|}{ Proposal } \\
\hline & \multicolumn{2}{|c|}{ Mouse } & \multicolumn{2}{|c|}{ Rat } & \multicolumn{2}{|c|}{ Monkey } & \multicolumn{2}{|c|}{ Dog } & \multicolumn{2}{|c|}{ Bear } \\
\hline & Yes & No & Yes & No & Yes & No & Yes & No & Yes & No \\
\hline \multicolumn{11}{|c|}{ Factors related to the experiment } \\
\hline Benefits & 65 & 74 & 81 & 91 & 96 & 47 & 72 & 16 & 87 & 79 \\
\hline Costs & 75 & 80 & 91 & 81 & 73 & 50 & 45 & 35 & 93 & 76 \\
\hline Validity & 12 & 4 & 5 & 19 & 11 & 32 & 5 & 3 & 8 & 15 \\
\hline Alternatives & 3 & 16 & 1 & 30 & 2 & 17 & 13 & 56 & 0 & 0 \\
\hline $\begin{array}{l}\text { Likelihood of } \\
\text { success }\end{array}$ & 3 & 2 & 9 & 8 & 3 & 16 & 1 & 1 & 1 & 0 \\
\hline $\begin{array}{l}\text { Experimenter's } \\
\text { motives }\end{array}$ & 0 & 11 & 0 & 0 & 0 & 3 & 1 & 1 & 3 & 24 \\
\hline
\end{tabular}




\section{Factors Related to the Experiment}

The third major category of decision-making themes concerned factors related to structural aspects of the research. These included statements of concerns about experimental design, the potential application of the results to human problems, and the motivations of the researchers (see Table 7).

\section{Benefits and Costs}

Many subjects said that the costs and benefits of the research entered into their decision-making process. Benefits and costs were sometimes evaluated in terms of numbers. For example, subjects wrote that the suffering of "only 20 monkeys" was justified when balanced against the potential elimination of a disease that strikes many millions of humans. Another wrote that the "inconvenience" of a few grizzly bears for research that might enhance the prospects of survival of the species was an easy tradeoff.

Benefits. There were substantial differences as to what individuals considered a legitimate benefit of the research. One subject described the learning demonstration with rats as "useless and completely absurd," whereas another called it "a good learning experience." Discussions of benefits often reflected anthropocentrism. One subject, for example, wrote, "Where there is considerable potential to salvage a human life, the research should be granted."

Medical, educational, and scientific benefits were evaluated. Not surprisingly, the types of benefits discussed varied with the proposal-scientific benefits with mouse and bear proposals, educational benefits with rat and dog proposals, medical benefits with the monkey proposal, and benefits to animals in the cases of the dog and bear proposals. For some, any potential benefit to humans, including nonapplied research, justified the use of animals. Others, however, felt that only experiments that were directly applicable to humans' problems justified the use of animals. In discussing his decision to reject the mouse amputation study, one individual wrote, "I don't see any purpose. The only justified benefit is practical knowledge." Several individuals wrote that medical experimentation provided the only morally acceptable context for animal research. In contrast, several others held that research with animals should only be conducted if it has direct benefit to other nonhuman species.

Costs. Both long-term and immediate costs were weighed in the decision-making process. Immediate costs included pain, harm to the animals, and financial costs associated with research. The participants disagreed over the degree of suffering animals would endure as a result of experimental procedures-Brain surgery was referred to as an "unfortunate disturbance" by one participant but as "horrible torture" by another.

Long-term costs of the research included the quality of life of animals after the experiment was completed and their ultimate fate. Would the animals be euthanized after the study? How much long-term suffering would mice actually undergo as a result of amputation of the forelimbs? One participant wrote, "The poor, innocent, little mice would be overstressed from not having a normal life-not being able to groom or feed themselves." Others, however, did not see amputation as a major issue because the mice would "never know what they were missing" by not having forelimbs.

A few participants described the advantages of being an experimental animal. For example, one wrote, "The care and feeding [in the laboratory] is high quality (much better than in the wild)." Another said that being a subject in an experiment caused less suffering than "being ripped apart by a tiger" or "poisoned and trapped." 
The validity of the research was mentioned by several participants as a factor that they considered in their approval decision. One participant wrote, "There are too many flaws in this idea so how can conclusions be drawn?" Others suggested modifications to the experimental procedures: "I say take really old monkeys because that's the way it usually would be performed on humans."

\section{Alternatives}

Subjects who wrote that there were alternative procedures that could provide similar information to the proposed research without the use of animals generally disapproved of the proposals. Alternatives were suggested for all of the proposals except the bear study. Subjects recommended incorporating films and videotape into college and veterinary courses instead of demonstrations and practice on live animals. One participant suggested that veterinary students "practice on cadavers like medical students do." Participants also suggested that veterinary students undergo extended internships rather than practice surgeries on healthy animals. In the case of the rat-learning demonstration, a participant succinctly wrote, "Let them read about it."

Subjects who wrote that alternatives to the use of animals were not available generally approved the proposals: "I wish they didn't have to be killed, but if it's the only alternative, then it must be done." Several subjects offered pleas to search for more humane ways to obtain similar information. One simply stated, "There's got to be a better way."

\section{Likelihood of Success}

Some subjects wrote that the likelihood that the research would succeed was a consideration for them. Students were more likely to reject experiments that they felt might fail. One participant wrote of the monkey experiment, "But what happens if the experiment is wrong and it doesn't work? You just killed 20 innocent monkeys!" Scientists may find this logic ironic. Ultimately, there is little point in conducting experiments if the outcomes are foregone. Experiments were also rejected if the subjects perceived the research repetitive. For example, a participant wrote of the rat classroom learning demonstration, "This has been done hundreds of times! Get a movie!"

\section{Experimenter's Motives}

The motivations of the experimenter was a salient factor in the decisions of a few subjects. Although the descriptions of the research contained no information about the motives of the researcher, some respondents wrote that scientists were driven generally by the search for trivial knowledge and the need for publications and research funds. As one individual wrote, "This is unneeded, useless research to please a sick mind." Another said, "She [the researcher] only wants the information for herself." Some subjects worried about sadistic tendencies of researchers, "Does he get a kick out of being cruel to little babies?" and "She just wants to use the information against the bears." Participants who considered the experimenter's motivation usually rejected the proposal.

\section{DISCUSSION}

Some general trends emerged from the thematic analysis of the written statements. Some themes were more common than others and, as in the case of cost-benefit analysis, were applied to all five proposals. Other themes were not common and were proposal specific. In some cases, the same line of moral thinking was used by both those who approved and those who rejected the proposal. For example, $73 \%$ of the 116 subjects who approved of the rat study indicated that they conducted a cost-benefit analysis. 
But $75 \%$ of the 36 subjects who rejected the proposal also said that they conducted a cost-benefit analysis. In contrast, some types of thinking were only manifested by rejecters or approvers. Relatively few subjects evaluated the experimenter's motivation, and those who did almost inevitably rejected the proposals. Similarly, subjects who felt that there were alternatives available almost invariably rejected the proposal. Of the subjects who rejected the rat proposal, 30\% mentioned the existence of alternative procedures, whereas only $1 \%$ who approved the proposal wrote that there were available alternatives.

Gender emerged as a statistically significant factor in several aspects of the first part of the study. Thus, we examined the frequency with which men and women invoked the various themes previously described. There was no evidence of a gender difference in the pattern of themes described in the narratives; male and female participants did not differ in the relative frequency that the various themes were found in their narratives.

\section{GENERAL DISCUSSION}

A complex web of factors entered into our subjects' decisions to accept or reject the use of animals for research or educational purposes. The factors that they reported to have considered in their decisions fell into approximately 20 the matic categories. The themes ranged from the rational to the emotional, from the practical to the philosophical. Our respondents sometimes used quite different paths of reasoning to arrive at the same decision to reject or accept a proposal. By the same token, subjects who said they used the same factors in thinking about the proposals sometimes came to opposite conclusions.

This finding points to the difficulty of constructing simple decision trees that would lead the members of an IACUC to the "right" decision. For example, Driscoll and Bateson ( 1988) proposed a model describing the factors that ought to be considered in making decisions. The major dimensions were the degree of suffering, the potential payoff of the research, and the quality ofthe experimental design. Although this model is elegant and fits moral intuition, problems arise, particularly in regard to the assessment of the dimensions. Presently, we cannot objectively assess how much suffering a rat deprived of food for $23 \mathrm{hr}$ undergoes or the long-term benefit of a study of development of grooming patterns in amputee mice. Our data indicate that individuals given the same description of an experiment differ in their evaluations of the degree of suffering to be experienced by the animals, as well as magnitude of the potential benefits.

Finally, as Rowan (1990) suggested, qualitative and quantitative analyses provided complementary information on aspects of human-animal relations. Both sets of data indicate that rational factors (e.g., cost-benefit analysis) and emotional factors (e.g., how upsetting the experiment was to the subject) interact to produce the final decision to reject or approve research.

Our methods have the drawbacks inherent in self-report studies. We assume that our subjects tell us the truth. In reality, some people may be reluctant to admit that certain factors played a role in their moral judgment process. For example, we were surprised at how few subjects wrote that the physical appearance of the animals played a role in their thinking. It is possible that this factor entered into the decision-making process of other subjects but that they were reluctant to admit it. Research in which people are asked to describe their mental processes assumes that they have access to these processes and, further, that they can put their thoughts into words.

In addition, we are uncertain as to the temporal relationship between the apparent decision-making process and the decision itself. It is possible that our participants, upon reading the proposals, quickly decided to approve or reject proposals based on "gut feeling" and only subsequently came up with the justifications. That is, the logic of decision making may postdate the decision. 
Despite these provisos, the use of hypothetical research proposals proved successful in elucidating a broad range of factors relevant to judging ethical dilemmas involved in the use of animals in research. The analysis of the processes that individuals report that they consider while resolving ethical dilemmas offers insight into the psychology of moral judgment. When we do not understand how an individual arrives at a particular position, it is difficult to view their position as credible.

The complexity of this type of decision-making process illustrates the diversity of attitudes regarding the use of animals in research. Understanding the processes individuals bring to bear on moral dilemmas involving the use of animals may open avenues of communication among those voicing opposing views on the animal research issue. Although perfect consensus may not be achievable, understanding and compromise may be within reach.

\section{REFERENCES}

Arluke, A. B. (1988). Sacrificial symbolism in animal experimentation: Object or pet? Anthrozoos, 2, 97116.

Baird, R. M., \& Rosenbaum, S. E. (1991). Animal experimentation: The moral issues. Buffalo, NY: Prometheus.

Burghardt, G. M., \& Herzog, H. A., Jr. (1980). Beyond conspecifics: Is Brer Rabbit our brother? BioScience, 30, 763-768.

Driscoll, J. W. (1992). Attitudes toward animal use. Anthrozoos, 5, 32-39.

Driscoll, J. W., \& Bateson, P. (1988). Animals in behavioural research. Animal Behaviour, 36, 1569-1574.

Dunlop, J. (1989). Moral reasoning about animal treatment. Anthrozoos, 2, 245-258.

Forsyth, D. R. (1980). A taxonomy of ethical ideologies. Journal of Personality and Social Psychology, 39, 175-184.

Forsyth, D. R., \& Pope, W. R. (1984). Ethical ideology and judgments of social psychological research: Multidimensional analysis. Journal of Personality and Social Psychology, 46, 1365-1375.

Gallup, G. G., \& Beckstead, J. W. (1988). Attitudes toward animal research. American Psychologist, 43, 474-476.

Galvin, S. L., \& Herzog, H. A., Jr. (1992). Ethical ideology, animal rights activism, and attitudes toward the treatment of animals. Ethics \& Behavior, 2, 141-149.

Herzog, H. A., Jr. (1988). The moral status of mice. American Psychologist, 43, 473-474.

Herzog, H. A., Jr. (1990). Discussing animal rights and animal research in the classroom. Teaching of Psychology, 17, 90-94.

Herzog, H. A., Jr., Betchart, N. S., \& Pittman, R. (1991). Sex role identity and attitudes toward animals. Anthrozoos, 4, 184-191.

Jasper, J. M., \& Ne1kin, D. (1992). The animal rights crusade. New York: Free Press. 
Kellert, S. R. (1988). Human-animal interactions: A review of American attitudes to wild and domestic animals in the twentieth century. In A. N. Rowan (Ed.), Animals and people sharing the world (pp. 137175). Hanover, NH: University Press of New England.

Knox, M. L. (1991). The rights stuff. Buzzworm: The Environmental Journal, 3, 31-37.

Patton, M. Q. (1990). Qualitative evaluation and research methods. Newbury Park, CA: Sage.

Pious, S. ( 1991 ). An attitude survey of animal rights activists. Psychological Science, 2, 194-196.

Regan, T. (1983). The case for animal rights. Berkeley: University of California Press.

Rollin, B. E. (1981). Animal rights and human morality. Buffalo, NY: Prometheus.

Rowan, A. N. (1990). Methods of searching for "truth." Anthrozoos, 4, 71-72.

Singer, P. (1975). Animal liberation. New York: Avon.

Weunsch, K. L., George, P. S., Poteat, G. M., Castel1ow, W. A., \& Pryor, W. H. (1992, June). Ethical ideology and suppon for animal research. Paper presented at the meeting of the Animal Behavior Society, Kingston, Ontario. 